\title{
Perundungan Dunia Maya (Cyberbullying) dan Upaya Preventif di Kalangan Siswa SMK Bangun Persada Bekasi
}

\section{Fransiska Novita Eleanora*1, Rabiah Al Adawiah²}

\author{
1,2Fakultas Hukum, Universitas Bhayangkara Jakarta Raya, Indonesia \\ *e-mail: $\underline{\text { ransiska.novita@dsn.ubharajaya.ac.id }}^{1}$ rabiah.adawiah@dsn.ubharajaya.ac.id $^{2}$
}

\begin{abstract}
Abstrak
Perkembangan dan maraknya akan kecanggihan dari teknologi yang semakin pesat dan juga berkembang mengakibatkan dampak yang positif dan juga yang negatif, dimana berdampak positif dengan penggunaan dari sosial media memberikan kemajuan dan juga ilmu pengetahuan serta dapat bertukar informasi antara yang satu dengan lainnya, sedangkan yang berdampak dalam yang negatif yaitu dikarenakan terjadinya hak-hal yang tidak diinginkan melalui media sosial seperti facebook, juga instagram, terjadinya intimidasai, saling mencemoohkan dan akibatnya dapat merugikan antara yang satu dengan lainnya, dan sebelum terjadinya akibat yang terkhusus berdampak kepada anak tentunya dapat dilakukan tindakan preventif dan pencegahan, dikarenakan anak terkadang perlu mendapatkan pengawasan dan kontrol baik dari orang tuanya dilingkungan keluarag, juga gurunya disekolah agar anak tidak menjadi pelaku dan juga korban dari cyberbullying. Permasalahan yang akan dikaji bagaimana upaya preventifyang dilakukan agar dapat terhindar dari pelaku dan korban cyberbullying. Tujuannya untuk mengetahui pencegahan yang dilakukan oleh siswa sebagai bentuk upaya yang preventif agar dapat terhindar dari perundungan di dunia maya, metode yang digunakan dengan ceramah dan diskusi dengan tanya jawab melalui aplikasi zoom dan hasilnya bahwa siswa sudah dapat mengetahui dan memahami upaya preventif dalam perundungan dunia maya (cyberbullying) berseta aspek hukumnya.
\end{abstract}

Kata kunci: Perundungan Dunia Maya, Preventif, Siswa

\begin{abstract}
The development and rampant sophistication of technology that is increasingly rapidly and also developing results in positive and negative impacts, which have a positive impact with the use of social media providing progress and also knowledge and being able to exchange information with one another, while the impact on The negative is due to the occurrence of unwanted rights through social media such as Facebook, also Instagram, the occurrence of intimidation, ridicule and the consequences can be detrimental to one another, and before the occurrence of consequences that specifically affect children, of course, preventive and preventive actions can be taken. prevention, because children sometimes need to get good supervision and control from their parents in the family environment, as well as their teachers at school so that children do not become perpetrators and also victims of cyberbullying. The problem that will be studied is how preventive efforts are carried out in order to avoid perpetrators and victims of cyberbullying. The aim is to find out the prevention carried out by students as a form of preventive effort in order to avoid bullying in cyberspace, the method used with lectures and discussions with questions and answers through the zoom application and the result is that students are able to know and understand preventive efforts in cyber bullying. (cyberbullying) and its legal aspects.
\end{abstract}

Keywords: Cyberbullying, Prevention, Students

\section{PENDAHULUAN}

Perkembangan dari kecanggihan teknologi yang semakin pesat dan marak mengakibatkan adanya perubahan dalam kehidupan baik yang positif maupun negatif, dimana perubahan yang positif dapat mengembangkan adanya ilmu pengetahuan serta dapat bertukar informasi antara yang satu dengan yang lainnya, sedangkan yang negatif terkadang dari penggunaannya di media sosial sering menimbulkan tindakan atau perbuatan yang tidak bertanggungjawab dan tanpa disadari sampai adanya korban dari perbuatan tersebut. Kondisi akan kesehatan dan mental dari korban cyburbullying perlu diperhatikan karena tidak hanya berkaitan dengan psychological distress, tetapi juga sangat berkaitan dengan psychological wellbeing yang merupakan efek dari individu yang juga positif (Ningrum \& Amna, 2020). Disamping 
itu Komunikasi yang paling alternatif untuk mempersingkat jarak dan juga waktu dan sangat digemari di kalangan anak-anak hingga sampai kalangan dewasa. (Nurul \& Murni, 2020).

Kemajuan dari adanya media informasi dan teknologi sudah sangat dirasakan oleh seluruh lapisan dari masyarakat (Yuhandra et al., 2021), dan juga sosial media merupakan sarana untuk melakukan interaksi yang sosial dengan menngunakan teknologi berbasis yang website untuk mengubah komunikasi yang menjadi diaolg yang interaktif yang dapat diakses dan terukur (Sukmawati \& Kumala, 2020).

Akibat dari perbuatan yang terjadi dengan menimbulkan sarana teknologi di sosial media dengan fasilitas facebook dan juga instagram serta yang lainnya, dimana dalam penggunaannya tanpa disadari atau bahkan disadari menimbulkan akibat dan terjadinya tindak pidana seperti pencemaran nama baik, juga penghinaan serta tindakan intimidasi atau diskriminasi seseorang atau kelompok tertentu dan akibatnya berdampak tidak baik bagi orang lain. dan inilah yang disebut dengan perundungan dari dunia maya atau cyberbullying karena dilakukan di media sosial.

Dalam bermedos setidaknya mempunyai etika sebagai user dan juga netizen beretika yang baik walaupun ada peraturan yang tertulis dan memiliki hubungan yang sebab dan akibat dari sikap seorang user saat bermedsos (Alexander \& Putranto, 2021). Bentuk dari perundungan terhadap dunia maya juga beragam salah satunya adalah flaming yang merupakan bentuk dalam mengirimkan pesan-pesan yang bernada kasar dan juga vulgar tentang seseorang pada sebuah kelompok online atau juga melalui email dan juga pesan yang lainnya (Sartana \& Arifyeni, 2017).

Pemahaman dari siswa mengenai perundungan dari dunia maya ini bukan saja dilakukan oleh orang dewasa, tetapi juga dilakukan oleh anak di bawah umur dimana dalam penggunaannya seharusnya anak tidak saja dibiarkan sendiri tetapi harus selalu dilakukan pengawasan dan dikontrol oleh orang tuanya di dalam lingkungan keluarganya, sehingga anak tidak terjerumus dalam suatu perbuatan yang dapat merugikan orang lain, dan pengawasan juga dapat dilakukan di lingkungan sekolah, dimana anak mendapatkan ilmu pengetahuan dan bimbingan dari gurunya, sehingga dengan adanya pengawasan dari sekolah dapat dilakukan pencegahan agar anak tidak menjadi korban dan pelaku dari tindak pidana cyberbullying, dikarenakan anak masih memerlukan perlindungan akan hak-haknya walaupun ada juga undang-undang informasi dan transaksi elektronik yang mengaturnya.

Perspektif dalam sistem dari cyberbullying adanya keterkaitan yang kompleks dalam lingkungan di sekitanya yang turut dalam membentuk dirinya (Fazry \& Cipta, 2021). Bahkan adanya upaya pencegahan dengan adanya pelatihan literasi yang digital yang diberikan kepada anak muda atau kaum millenial mengingat adanya target dari khayalak dan harus dijangkau sangat besar maka sangatlah dibutuhkan peran dan serta dari berbagai pihak untuk selalu menggaungkan akan pentingnya literasi digital (Maria \& Lemona, 2019). Untuk itulah, agar tidak menimbulkan korban dan pelaku maka perlu dilakukan pencegahan sedini dan semaksimal mungkin, pencegahan lebih bagus daripada mengobati yang dimana perlu dilakukan usahausaha preventif agar anak tidak terjerumus menjadi korban dari perundungan dunia maya (cyberbullying), sehingga perlu dilakukan upaya pencegahan atau preventif agar siswa tidak terjerumus terhadap tindakan dalam perundungan dunia maya yang dapat mengakibatkan dampak yang tidak baik bagi perkembangan siswa.

Berdasarkan latar belakang tersebut, maka permasalahan yang akan dibahas oleh Tim Abdimas adalah upaya pencegahan (preventif) yang perlu dilakukan oleh siswa agar dapat terhindari dari bahaya dab dampak perundungan dunia maya (cyberbullying) serta aspek hukum yang mengatur jika terjadi tindakan cyberbullying.

Tujuan dari kegiatan ini adalah meningkatkan pengetahuan dan pemahaman kepada Siswa SMK Bangun Persada Bekasi pentingnya upaya pencegahan agar dapat terhindar dan tidak terjerumus dalam bahaya dan dampak cyberbullying beserta aspek hukum yang mengaturnya. 


\section{METODE}

Kegiatan dalam pengabdian masyarakat berupa penyuluhan hukum ini dilaksanakan selama 1 (satu) hari yaitu Sabtu, 10 April 2021 dan menggunakan aplikasi zoom, diikuti oleh guru dan siswa dari Sekolah Menengah Kejuruan (SMK) Bangun Persada Bekasi, dan dari Pemateri disini dalam pelaksanaannya dengan ceramah dan juga presentasi dan dilaksanaakan dengan 2 (dua) pemateri dimana pemateri pertama menjelaskan mengenai pengertian perundungan dunia maya pada umumnya (cyberbullying), yaitu mengenai pengertian, dampak, serta faktor dan pemateri kedua menjelaskan dampak yang akan terjadi dan aspek cyberbullying dalam hukum pidana serta adanya ketentuan sanksi yang akan mengaturnya jika terjadi pelanggaran atau kejahatan yang berkaitan dengan informasi dan juga transaksi online. Dan setelah presentasi materi dilaksanakan lalu dibuka dengan sesi tanya jawab dari beberapa siswa yang ingin bertanya. Pelaksanaan dari penyuluhan hukum ini dipandu oleh moderator yang sebelum mulainya membuka dengan menjelaskan maraknya perundungan dunia maya sehingga dalam penggunaaannya di media sosial harus selalu berhati-hati dan waspada serta bijak dalam penggunaannya supaya tidak terjerumus dalam bahaya yang akibatnya dapat merugikan orang lain dan diri sendiri, seperti dapat merusaknya kesehatan fisik dan juga mental, dengan adanya penyuluhan hukum ini maka siswa dan siswi dapat meningkatkan pemahaman mengenai pentingnya pencegahan akan perundungan dari dunia maya (cyberbullying) dan dilaksanakan dengan upaya preventif agar tidak menjadi pelaku dan korban dari tindakan cyberbullying.

\section{HASIL DAN PEMBAHASAN}

Kegiatan dalam pengabdian masyarakat ini berupa penyuluhan hukum yang diikuti oleh siswa dan siswi dari SMK Bangun Persada Bekasi dengan jumlah 32 orang dan dilaksanakan pada hari Sabtu, 10 April 2021 dengan aplikasi zoom dan dilaksanakan selama 2 (dua) jam yaitu sekitar 120 menit. Adapun hasil yang dicapai dari pengabdian kepada masyarakat melalui penyuluhan hukum cyberbullying dan upaya preventif di kalangan siswa:

a. Para peserta/siswa antusias dalam mengikuti kegiatan yang ditandai dengan ikut sertanya para siswa meskipun jadwal belajar yang padat karena menjelang Ujian Tengah Semester (UTS) dan hanya melalui aplikasi zoom.

b. Peserta atau Siswa aktif dalam sesi tanya jawab.

c. Peserta atau Siswa mengerti dan memahami materi yang diberikan tentang bahaya, dampak, dan aspek hukum dari cyberbullying.

Sedangkan pembahasan diadakannya kegiatan dari penyuluhan hukum ini kepada siswa dan siswi mengenai cyberbullying dan upaya preventif di kalangan siswa, mereka dapat memahami pengertian, elemen, karakteristik dan penyebab serta dampak dan pencegahannya agar tidak menjadi korban dan juga pelaku dari perundungan di dunia maya (cyberbullying) serta aspek hukum dari perbuatan tersebut. Dibawah ini adalah penyampaian materi oleh pemateri 1 mengenai Perundungan dari Dunia Maya (Cyberbullying) terkait pengertian, elemen, karakteristik, dan penyebabnya.

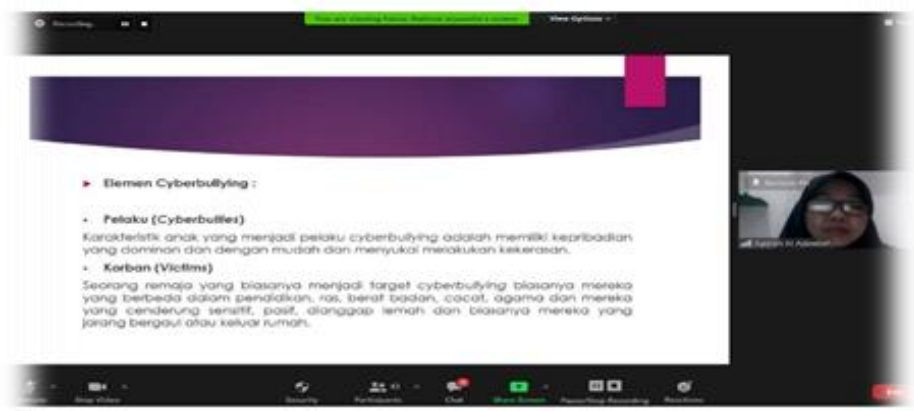

Gambar 1. Pemaparan Materi Cyberbullying 
Penyampaian materi oleh pemateri 2 mengenai aspek Hukum dari Perundungan Dunia Maya (Cyberbullying) dan penerapan sanksi atau pidananya ditunjukan oleh gambar berikut.

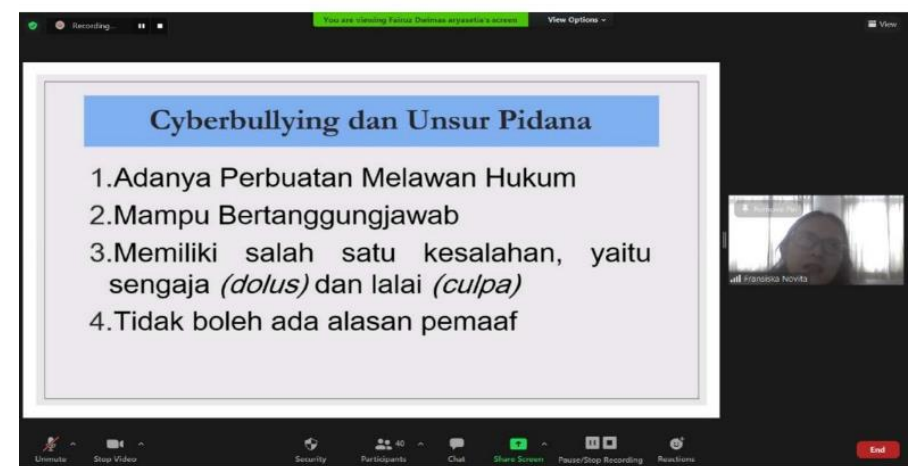

Gambar 2. Pemaparan Materi Cyberbullying dari Aspek Hukum

Adapun dokumentasi peserta penyuluhan hukum melalui aplikasi zoom mendengarkan presentasi yang disampaikan oleh pemateri 1 dan pemateri 2 adalah sebagai berikut.

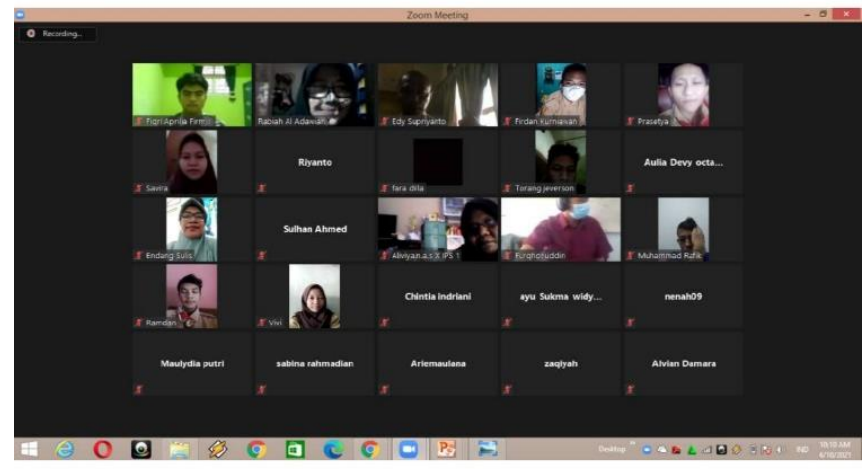

Gambar 3. Para peserta penyuluhan hukum

Tabel 1. Hasil dari dilaksanakannya kegiatan pengabdian masyarakat

\begin{tabular}{|c|c|c|}
\hline & Sebelum Kegiatan & Sesudah Kegiatan \\
\hline $\begin{array}{l}\text { Bahaya perundungan dunia } \\
\text { maya (cyberbullying) dan } \\
\text { dampaknya. }\end{array}$ & $\begin{array}{lrr}\text { Belum mengetahui } & \text { dan } \\
\text { memahami } & \text { bahaya } & \text { dan } \\
\text { dampaknya. } & & \\
& & \end{array}$ & $\begin{array}{lrr}\begin{array}{l}\text { Sudah } \\
\text { mengerti }\end{array} & \text { bahayami } & \text { dan } \\
\text { dampaknya. } & & \text { dan } \\
& & \end{array}$ \\
\hline $\begin{array}{l}\text { Aspek hukum dalam } \\
\text { cyberbullying serta penerapan } \\
\text { sanksinya. }\end{array}$ & $\begin{array}{l}\text { Belum mengerti akan aspek } \\
\text { hukum dan juga penerapan } \\
\text { sanksi dalam cyberbullying. }\end{array}$ & $\begin{array}{l}\text { Sudah mengerti dan } \\
\text { memahami akan aspek hukum } \\
\text { dan juga penerapan sanksi } \\
\text { dalam cyberbullying jika } \\
\text { terjadi perbuatan pidana. }\end{array}$ \\
\hline $\begin{array}{l}\text { entif) } \\
\text { bagai }\end{array}$ & $\begin{array}{l}\text { Belum mengerti dan } \\
\text { memahami upaya pencegahan } \\
\text { (preventif) sehingga dapat } \\
\text { terhindar sebagai pelaku dan } \\
\text { juga korban. }\end{array}$ & $\begin{array}{l}\text { Sudah dapat mengerti dan } \\
\text { memahami upaya pencegahan } \\
\text { (preventif sehingga dapat } \\
\text { terhindar sebagai pelaku dan } \\
\text { juga korban. }\end{array}$ \\
\hline
\end{tabular}

\section{KESIMPULAN}

Hasil kegiatan dari penyuluhan hukum ini siswa dan siswi sudah mengerti dan memahami akan bahaya dan aspek hukum serta upaya pencegahan dari perundungan dunia maya (cyberbullying), dimana dengan pelaksanaan kegiatan ini juga dapat meningkatkan pemahaman siswa dan siswi Sekolah Menengah Kejuruan (SMK) Bangun Persada Bekasi untuk 
dapat menggunakan media sosial secara bijak dan hati-hati agar dapat terhindar dari bahaya dan dampaknya, beserta aturan hukum yang mengaturnya yaitu undang-undang mengenai informasi dan transaksi elektronik.

\section{DAFTAR PUSTAKA}

Alexander, E. \& Putranda Kristianto, R. (2021). Penyuluhan Cyber Space: Cyber Bullying dan Etika Bermedsos untuk Meningkatkan Wawasan Internet Sehat Beserta Pengukuran Tingkat Kepuasannya. Jurnal Pengabdian Kepada Masyarakat DEWANTARA, 4 (1)

Fazry, L. \& Cipta Apsari, N. (2021). Pengaruh Media Sosial Terhadap Perilaku Cyberbullying Di Kalangan Remaja, Jurnal Pengabdian dan Penelitian Kepada Masyarakat (JPPM), 2 (1)

Maria, P. J. \& Lemona, M. (2019). Literasi dan Sosialisasi Internet Ramah Anak, ABDI MOESTOPO Jurnal Pengabdian Pada Masyarakat, 2 (2)

Ningrum, F.S., \& Amna, Z. (2020). Cyberbullying Victimization Dan Kesehatan Mental Pada Remaja, INSAN Jurnal Psikologi dan Kesehatan Mental, 5 (1)

Nurul Intan, S.S., \& Murni, D.H.S. (2020). Pendampingan Penggunaan Media Sosial Yang Cerdas dan Bijak Berdasarkan Undang-Undang Informasi dan Transaksi Elektronik, Diseminasi: Jurnal Pengabdian Kepada Masyarakat, 2 (1)

Sartana., \& Afriyeni, N. (2017). Perundungan Maya (Cyberbullying) Pada Remaja Awal, Jurnal Psikologi Insight, 1 (1)

Sukmawati, A., \& Kumala A.P.B. (2020). Dampak Cyberbullying Pada Remaja di Media Sosial, Alauddin Scientific Journal Of Nursing (ASJN), 1 (1)

Yuhandra, E., Akhmaddhian, S., Fathanudien, A. \& Tendiyanto, T. (2021). Penyuluhan Hukum tentang Dampak Positif dan Negatif Penggunaan Gadget dan Media Sosial, Jurnal Pengabdian Masyarakat EMPOWERMENT, 4 (1) 


\section{Halaman Ini Dikosongkan}

